\title{
Engaging Students in Learning English Syntax through Text Analysis
}

\author{
Hermawati Syarif \\ English Department \\ Universitas Negeri Padang \\ hermawati_sy@yahoo.com
}

\begin{abstract}
Due to the boredom of students in learning syntax, a meaningful strategy should be created. This paper describes the activities of students in learning English syntax through text analysis for their mastery. It covers the discussion of forms from the texts given. In the meantime, the data were collected by observing, testing, and distributing questionnaires. The activities observed are classroom activities, namely students' assigned tasks, text analysis through three kinds of learning process (question-answer, pair work, and small group discussion) with problem solving activities to get and apply the rules. The results show that the activities of analyzing text in learning syntax generally improve students' eagerness in doing tasks. Through four stages of activities, namely information transfer, language focus, the use of rules, and sentence analysis, the positive response from students shows the success of the learning activity. Working in pairs and groups were still the choice of students to help them comprehend the rules. In spite of students' low achievement in pre-test, their mastery in post-test improved impressively to $75.9 \%$. Constructing the utterances from the rules given motivates the students in analyzing text. However, there were still more students having problems on the basic rules of syntax such as parts of speech and word order especially for the low competent students. Further explanation on the rules of syntactical analysis will probably be helpful insights for future studies of the same kind.
\end{abstract}

Keywords-text analysis, syntax, problem solving activities

\section{INTRODUCTION}

Why should be text analysis? A text is a semantic unit; a unit of language that makes sense [1]. It is related to what people want to express and comprehend. By analyzing the text, the rules of language used can be examined, and simultaneously, the message read or listened can be comprehended.

Commonly, the way of analyzing text is based on the rules governed in the language analyzed. And grammar is the analysis of the properties characterizing well-formed sentences of the language [2]. Related to rules governed, linguistic subjects may become the target of text analysis. Syntax, as one of them, can seemingly be learned in this way.

In the sense of conducting the study, English Syntax has already been offered to fill the curriculum as one of the content subjects in English Department of FBS UNP. This field is under the subject of "Morphology and Syntax". The course aims at providing students with the knowledge and skills of how sentences are constructed from words. It covers phrases, clauses, and sentences and their transformations.

A fact showed that students thought the subject did not directly touch the language use. Thus, they were not really eager to learn syntax. Consequently, the impact was on the learning activities. The subject was taken only to fulfill the requirement of the curriculum so that the result of learning experience was low and disappointing.

There have been various ways of learning activities applied in this subject. They were lecturing, small group work, and pair work. However, they were still not really effective. Not all of the students were actively involved in the teaching learning process. It can be seen that students still had difficulty in understanding materials and lessons in syntax and of course, it is a hard way to obtain the objectives of this subject.

It is a crucial thing to find an appropriate technique that can be used to teach syntax and overcome problems faced by students. One possible model is the text analysis using the problem-solving technique. It is a technique through which the lecturer gives an opportunity to students to work in small groups and in pairs to solve problems, share information and opinions on problems, which are meaningful to them.

Students are asked to analyze text by solving problems through question-answer either in group discussion or in pairs. This technique involves collaboration and self-initiation in language learning. In groups, students share ideas with their friends in order to avoid monotony. To help them avoid their boredom, students get a new text each week. Hence, they can actively be involved in the teaching learning process and they understand the material in syntax.

Since students get the rules from analyzing the text by solving the problems, an inductive learning activity exists.

Syntax, as also said grammar, has been defined similarly to some linguists such as Radford (1999), Wilson (2001), Hellspong (2001), and Brown (2007) [3, 4, 5]. It is related to the formulation and interpretation of phrases and sentences in order to create an intended meaning. Thus, the 
relationships of words within a sentence can make a sense for the listeners or readers. Moreover, position syntax as one of the grammar studies which analyzes the possible forms (structures) in a language [6]. It concerns almost exclusively with the analysis at the level of the sentences.

The description of rules leads the language users to understand how the language sentences are formed when they listen, speak, read, and write. Learning syntax, then, is not only learning how to arrange words in a good order to form phrases, clauses, and sentences, but also paying attention to the rule of combining them. The correct sentence arrangement of a sentence based on the rules will make the readers get the meaning of the sentence easily.

When someone is reading a text, understanding isolated words is not adequate for the task of understanding the language. As it is known that all languages have rules regarding how words can be combined to form sentences, an implicit understanding of the rules of the sentence structures and phrases is also essential. When people string words together in order to form a sentence, the goal is to relay a specific message. The reader who looks at these arranged words uses syntax to determine what they mean.

Syntax, then, plays an important role in language. Without syntax, a string of words would simply make no sense. Getting it right is a large part of making a language useable [7]. Using the correct syntax in writing helps his readers get what he means in the texts. It can also be seen in stating an opinion in a sentence [8]. Let us have a look at sentence The kids love playing on the rains. This sentence is easier to understand for it follows the rule of subject, verb, and object agreement. It could simply be written, *Playing on the rain loves the kids. However, it has totally different meaning with incorrect arrangement, even though the class of words used is the same. Besides, there seems to be no agreement in this sentence since playing on the rain is an inanimate (activity) that cannot 'perform' a verb.

As a consequence, the teaching of syntax is not just to help students to learn syntactic concepts and theories but also to engage them in the further step of applying what they have learned in their practical use - to perceive, identify and produce grammatical sentences particularly in the written form. The students are led to see the use of different syntactic types in the authentic writing in newspapers or magazines. More specifically, they learn the types of syntactic structures commonly used in the real context by analyzing the syntactic constructions in the texts [9].

Informing the learners about the advantages that they can achieve by acquiring the knowledge of syntax is also an essential task to do since it will be applied to their perception and production in the target language, as well as the cognitive exercises in identifying, categorizing and analyzing linguistic units. All of these will sharpen their linguistic sensibilities and contribute to their language mastery.

For students of the advanced level, syntax is a subject which is best learned through practices [10]. It is a vital skill to practice through the analysis of sentences in text in order to understand how the language works and improves student's understanding to the subject. Analyzing a particular sentence will demonstrate that the students have some understandings of the meaning of grammar, the rules, the accepted usage and the meaning interpretation as well as its significance. Shortly, practicing what the students know by analyzing the text will help them to master the language.

The highest hierarchy component of syntax is sentences. In analyzing a sentence, principally pay attention to two types of descriptions which are syntactic class and syntactic function. The syntactic class refers to the grammatical properties like noun phrase and verb phrase while the syntactic function is related to the grammatical roles such as subject, predicate, and object.

It is the largest unit of grammar which is independent and expresses a complete idea with subject and verb as the constituents of sentences and also of clauses within sentences [11]. The subject is the person or thing that acts or is described in the sentence while the predicate (verb in Quirk term) is the action or description [12]. The basic parts of a sentence are the subject, verb and object [13]. The subject is usually a noun to indicate the name of a person, place or thing. The verb, which Scocco calls the predicate, follows the subject. It does not only identify an action but also the state of being. Meanwhile, an object usually follows the verb.

A sentence as a group of words which people use to communicate their ideas can also be formed from one or more clauses and expresses a complete thought $[14,15]$. Every English sentence is made up of basic building blocks, the parts of speech which consist of noun, verb, adjective, adverb, article, conjunction, preposition, and pronouns.

A sentence can also be categorized into four types, namely, simple, compound, complex, and compoundcomplex sentences. The sentence type is determined by the type of clauses used to form it. The compound sentence, for example, consists of two or more independent clauses or simple sentences and they are joined by using coordinating conjunctions. A complex sentence contains one independent clause and has at least one dependent clause. A compoundcomplex sentence has at least three clauses, and two of which are independent, yet very seldom occurs in text [15]. This categorization is what should be analyzed in the study of syntax.

The second component of syntax is a clause which is associated to sentence. There are two views on the concept of clauses; one is that a clause is a sentence and second is that it is a part of a sentence. In the first view, when we talk about clauses, what we mean is the sentence itself. Meanwhile, the second view is that of idea, stating that a clause refers to a sentence having the constituents of other sentences or phrases [16, 17, 18]. A clause contains a subject and a verb, which can or cannot contain a complete thought. In this sense, the second view will be taken as the concept of clauses.

Clauses may be classified into two kinds. A clause that has a complete thought, which can stand on its own as 
sentences are called either independent or main clauses, while clauses that are lack of complete thoughts are termed either dependent or subordinate clauses [15]. A dependent clause begins with a subordinator such as when, while, if, that, or who. It does not express a complete thought since it begins with a subordinator before the subject and is followed by a verb. In contrast, an independent clause contains a subject and a verb and often with complement [19].

A dependent clause, furthermore, is categorized into noun clause, adjective clause, and adverb clause. It is classified based on the role of each clause in the sentence, namely, as noun, adjective, or adverb. They are embedded to the independent clauses [20].

The smallest component of syntax is a phrase. It may consist of one or more words that are grammatically linked. One word phrase automatically functions as a head (such as Helen), while the phrase consisting of more words has a head and modifiers [21]. English has various kinds of phrases: adjective phrases (AdjP), noun phrases (NP), verb phrases (VP), adverb phrases (AdvP), and prepositional phrases (PP) (Wheeler, 1998). Each on them has the head except for the prepositional phrases. In PP, the preposition is called the relator of the phrase. Here are examples of each category (the bold type are the heads, except the Prep is a relator) :

$\begin{array}{lc}\frac{\mathrm{NP}}{\text { the }} & \frac{\mathrm{ch}}{\mathrm{VP}} \\ \mathrm{N} & \frac{\text { speak well }}{\mathrm{V} \mathrm{Adv}} \\ \frac{\text { AdjP }}{\text { quiet }} \frac{\text { difficult, }}{\text { Adj }} & \frac{\text { AdvP }}{\text { Deg } \frac{\text { quickly }}{\mathrm{Adv}}}\end{array}$

The coverage of syntax can be seen in any kinds of text. The students can use the text as a medium which enables them to practice English in the written form. The text is defined in any different ways. The first is any spoken or written passages of whatever length that does form a unified whole and the second is a combination of lexical and grammatical devices which shows cohesiveness and coherence in order to make sense of utterances [22, 6, 23].

In analyzing the text, several ways as material objects. One of them is the analysis of the structure of the text. To do the analysis, there are some questions that lead the students to comprehend the meaning of the texts. They are: What comes first? What comes after? How is it built? Is it a travelogue or a fantasy or a historical novel or a nonfiction work or poetry or what? Does it follow a timeline, a logical sequence, a problem-solution-resolution process, a simple list of items, a comparison and contrast analysis, a balance of forces analysis, or does it simply jump back and forth chaotically? How are the chapters and sections divided? What sort of language and imagery does the text contain? What style (tone) of language is used (high, medium, or low)? How good is the spelling, grammar, vocabulary and punctuation? [24].

The other is analyzing it by breaking it down into its components. The readers can examine different aspects of the text. They can also look at the word choice and the structure of the sentences used. The next search may be the transformation used in the text.

One interesting classification of text is based on its usage by acronymizing the classification into TALO (text analysis of linguistic object) [25]. It is used for language work especially when working with grammar and vocabulary, to which someone refers his/her statement on the text. The characteristics of TALO text are (1) it is written especially with the pedagogical purpose in mind, (2) it could be an authentic text that has been chosen by the lecturer because it contains many examples of a particular language feature, and (3) it could be an adapted authentic text that contains certain features of language. In can be concluded that TALO is suited to the analysis of syntax.

The syntax course should be learned by considering the importance of the text analysis. It focuses on the structure of the written language in order to provide a detailed linguistic analysis of texts. The students as readers are able to analyze the text syntactically with questions in their mind such as "How good is the grammar in the text?" They analyze the text in order to get the understanding on how words can be put together to have meaning. Then, the task is that the students will be asked to break down the sentences in text and analyze them syntactically.

Written texts differ from one another not only in genre and function, but also in their structure and form [26]. This written text is primary to language teachers, as the knowledge of arrangement and variety of writing that influences readers' understanding, memory of messages included in the discourse, as well as the speed of perception. Moreover, written texts analysis provides teachers with systematic knowledge of the ways of describing texts. In addition, understanding these concepts should also improve learners' writing skills as they would become aware of traits that are essential for a good written text.

Furthermore, analysis of texts also encourages students to reflect upon and critically evaluate knowledge acquired in the study of, for example, syntax and semantics as well as naturally draws students to the investigation of socially-situated language use. Even, it provides students with the opportunity to examine how meaning is constructed and negotiated in texts and to reflect on the role that language plays in the social life. It means that the students do not only try to find the rules to get the meaning in the text but also to know the role of the language.

The text analysis technique contributes to the students' understanding about the meaning of the text. The students can be good writers if they understand the construction of the text and how words are combined together to achieve a well-formed and meaningful sentence. Moreover, they can also understand the functions of the text. This technique will motivate the students to be critical thinkers because they examine, identify, and analyze the 
rules.

In short, text analysis helps students gain the rules of English from the text in syntax course comprehensively. Intensive practices through text analysis lead to the mastery of linguistics unit. By finding examples of the rules in the text (all the words/phrases/clauses in the text connected to the rules), students may apply what they know. The students will have the opportunity to look into the texts to examine what types of syntactic structures are used such as the types of subjects and predicate.

\section{METHOD}

It was the findings of a case study, which aims at helping the lecturer to solve the problems that are faced when she is teaching in the classroom. It was the research under which two students of S I who were taking thesis got the data. In the research, the technique used was text analysis, in which the students are required to analyze the text to get the rules in the process of learning. It involved two students who were in the process of doing the final project of their program as the assistant in collecting the data.

In monitoring and evaluation as the activities of observation, the field-note and Pre-Post test were prepared as the data collection to see the improvement of students and their problems. Informal interview was also conducted to make sure the data obtained. The reflection phase was formulated as the conclusion of the effect of the action seen from various criteria.

The activities are pictured out as follows.

Text Analysis Model

The framework of this model adapts the view of interaction of input, language, content, and task proposed by Djiwandono, in which task is changed by text analysis as seen in the following frame [27].

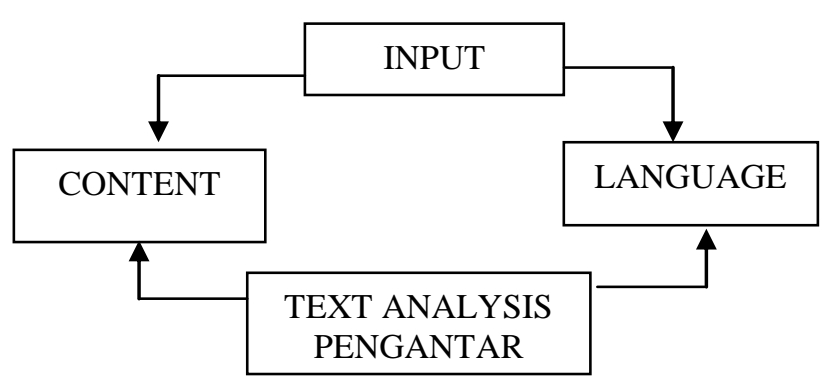

Figure 1. The Framework of Text Analysis Model

Text analysis is the center focus of the activities. Language and content drawn from the input and selected based on the topics being talked lead the students to do the analysis. Three kinds of techniques were varied in the classroom, namely, Question-Answer, Pair work, and Group work discussion as the descriptions of the activity. All activities were conducted by applying the text analysis. Operationally, the phase of introductory activities was suited to the theories referred. In formulating the implementation of the action, the improvement of delivering instructional materials is from the concept (rules) to the use of the rules in Syntax.

The activities of the students to use the informationprocessing skills in their first start of learning are regarded as the input. This input produces language items, the topic, and stimulus materials for next activities. Figure 2 shows the sample of model in which the activities vary based on the techniques used.

\section{Activity 1: Information Transfer}

Reading the materials of the topic in the syllabus is considered as the process of getting the information as the input. The information obtained from the book is transferred into the PS-rules and tree diagram as seen in figure 3 (as an elementary grammar). This activity is done by analyzing the sentences (text) prepared through question-answer, pair work, or small group discussion until they get the rules asked.

The information transfer, in daily communication, is a routine activity, in which the literate people put the information obtained into various forms of format, such as note, diagram, table, or graph. In the case of communicating syntax in the real use, students are trained to get in touch with comprehending the text through analysis for the rules. This information transfer should be done for several reasons.

Firstly, one needs to consider the target situation where students would eventually use English. When our students enter the work world, a part of their daily routine will be to attend to information transmitted orally or written in memos or letters. Later, they must transfer this information to another intelligible format.

Secondly, the activity fosters the development of new learning skills. Part of the content that the students have to learn is the grammar rules, and to some extent, this requires a degree of repetition combined with attention [27]. This requirement is sufficiently met in the information transfer activity because it incorporates repetition of certain structures [28].

Another advantage is related to the students' mind. Clearly, when they are pre-occupied with the listening and transferring tasks, they proceed in a thinking fashion. Finally, the information transfer activity carries a potential for subsequent activity. As Palmer notes, it forms a kind of pivot around which any of the language skills may revolve [28]. 


\section{Activity 1: Information Transfer}

The students

1. read the materials with the topic "Describing Sentence" at home and come up with the notes on the concept to the classroom,

2. discuss the materials in pairs by sharing the ideas on parts of a sentence based on the sentences (text) given,

3. find out the concept or rule (PSrules) from the sentences (text) given by drawing tree diagram(s).

Activity 2: Language Focus

The students

4. practice getting the rule from new sentences (text),

5. share ideas for the accuracy

Activity 3: Having Use of the Rule

The students

6. create their own sentences (text)

from the existing rule

7. exchange the result in pairs for discussion

Activity 4: Analyzing Sentences (Text)

8. The students analyze the text taken from any English newspaper as the assignment.

Figure 2. Text Analysis Model

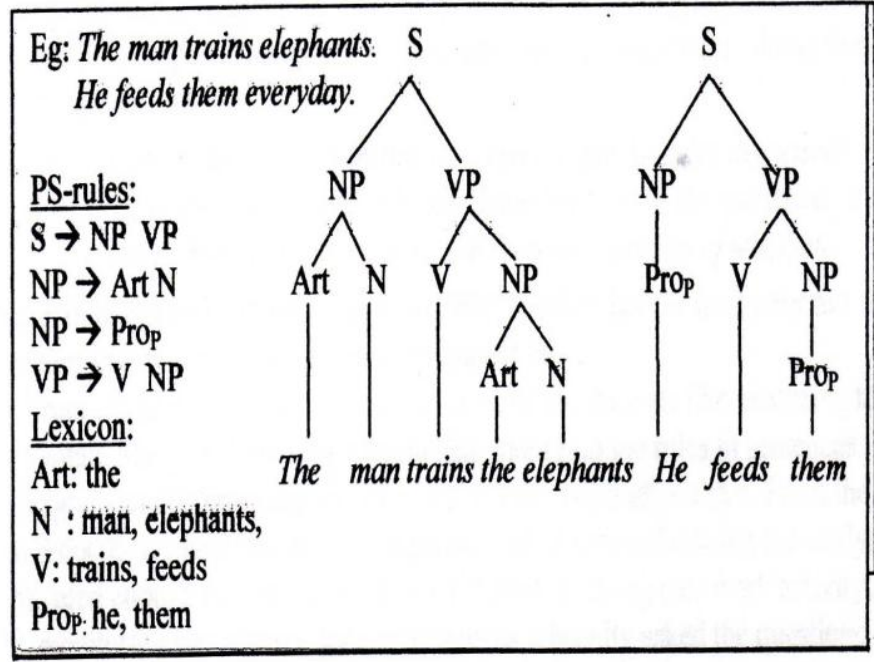

Figure 3. Elementary Grammar

\section{Activity 2: The Language Focus}

After getting the concept (the rule) of the topic discussed, the students continue the activities by searching the rule from other sentences of the text assigned. This practice is undertaken by sharing ideas in form of having question and answer, discussing in pairs, or in small group discussion to reach the accuracy. It is the instructor's time to give the feedback and reinforcement on the students' work at the end of their activity.

\section{Activity 3: Having Use of the Rule(s)}

This activity is going on with creating new sentences (text) based on the rule discussed. Unlike in activity 2, students do it individually. Any text they make always refers to their existing knowledge on PS-rule. Besides, their experience and their background knowledge will help them write accurate sentences or text. Then, they exchange their work and discuss them. Again, the role of the instructor is headed for feedback and reinforcement.

\section{Activity 3: Analyzing Sentences (Text)}

As a post activity, the students are assigned to analyze the text taken from the newspaper. The texts prepared are varied. The purpose is that more text analysis emerges from students learning activities. Since the text does not always consist of the pattern discussed, the students are asked to analyze the learned rules from the text. Generally, this activity is done as the homework. As the feedback, the chance is given to the students with the confusion on the task before the next meeting starts.

\section{FINDINGS AND DISCUSSION}

Since the model is applied in the classroom activities, the findings shown rely on the activities done. Because the students were already assigned to read the concept before coming to the classroom, at least they have got general concept about the topic discussed. Probing questions to call forth their comprehension to what they have read got good responses. The students were enthusiastic in answering questions. The questions led them to get the true concepts of the rules.

Before starting to analyze the text, general description on the activities was explained. It included the materials and some examples of the sentences, phrases or clauses to be analyzed as well as how they did the activities (question-answer, pair-work, or small group work). This general explanation could help the students to comprehend the materials before doing the analysis. It is pictured out from the data of interview

Interviewer : Can the lecturer's questions lead you to get the rules discussed?

Student 9 : Of course. it really leads me. Sometimes, from the questions, it reminds me the definition of preposition, the sentence contains of what, etc.

This explanation supports Bertrand's opinion (2009), stating that the instructor has to explain the procedure and 
demonstrate which activity should be done in pair work and group work.

From the findings, it was found that most of the students are fond of analyzing text in learning syntax. Many of them said it could help them to find the rules in sentences. Drawing the tree diagram and determining the PS-rules seem motivating to them. From the data observed, it was faund that most of the students looked serious in doing the analysis and were motivated enough in doing this activity (78.5\%). In doing the pair work activity, for example, monitoring was always done and students asked the questions on the problem they faced. Their enthusiasm also emerged because the result of their analysis was discussed so that they convinced themselves to have done it well. They have transferred the information of the text to the form of the language (rules).

Related to the rules of syntax tested, constructing the phrases, clauses and sentences is in the first place. The followings are the sample of data of such rules with the symbols given. The italic utterances are students' work.

1. Adv V Art Adj $\mathrm{N} \rightarrow$ Carefully ride the black horse. 2. Adj N N prep Dem Adj $\mathrm{N} \rightarrow$ great clock tower in that great city

3. Pro $_{\mathrm{S}} \mathrm{N}$ VL Art Deg Adj N $\rightarrow$ His brother is the most popular singer.

4. $\mathrm{Cj}_{\mathrm{Cl}}$ Pro $_{\mathrm{p}} \mathrm{V}$ Prt $\mathrm{N} \rightarrow$ that he cleaned up motocycles

These utterances show that the symbols of the rules have been fulfilled with meaningful context.

However, some of the students who have low ability in learning syntax sometimes looked confused in analyzing the text and breaking a sentence into its components. It could be seen from their overall activity. The text was difficult to be analyzed for them. The interview data show that it is be caused by the student's ability in mastering previous grammar lessons. As a continuation of the grammar lesson, syntax is a burden to them. Since they did not have well self-concept and interest, they were not motivated in learning.

The response of the students on the text assigned to be analyzed was good. $77.3 \%$ of students show their good responses on the text used to find the concept of the topic. The text to them plays as media that help them understand the materials. It can be understood that the text gotten from newspaper could be easily comprehended since it is authentic and related to the real use. This makes them easy to get the PS-rules of sentence and its components in the text. The students felt convenient and helpful by the activities of sharing ideas with friends whether in pairs or in small groups as well as the feedback and/or reinforcement the instructor at the end of the activity. In other words, the text was really helpful for the students in studying syntax. This is in line with Thornbury's and Harmer's who mention that it is better to use texts for teaching grammar [6].
However, it cannot be avoided that some students still did not really care about the task given through discussion since they have lack competences in grammar.

Related to the concept application that is to construct the utterances or sentences based on the rules governed, some of the students could not finish their job on time. They had to stop their work though they have not finished it yet. Since the time provided was limited, this seemingly becomes the problem. Besides, their individual difference in getting the ideas is also problematical. It is assumed that the time-on-task contributes to individual differences in the academic skills.

However, the utterances they constructed were mostly accurate. As an example of a sentence done with the rule of

$\mathrm{NP} \rightarrow \mathrm{NP}$ Cjc NP is $\frac{\text { This }}{\underline{\mathrm{NP}}} \underline{\frac{i s}{\mathrm{VL}}} \frac{\text { a good chance }}{\underline{\mathrm{NP}}} \frac{\text { and }}{\text { Cjc }} \frac{\text { an exact }}{\underline{\mathrm{NP}}}$

time.

Concerning with the individual task assigned, students were eager to analyze for the patterns assigned at home with their searched text. Their eagerness might have also increased because of the peer correction and feedback given. $73 \%$ of them completed their analysis at home with the accuracy of $80 \%$. Meanwhile, their achievement on the materials given was high enough. The average was $77 \%$. The percentage is good for syntax class along my experience teaching this subject. The very important thing to note down is that students have already realized that syntax can give them confidence in constructing well-formed sentences or texts.

\section{CONCLUDING REMAKS}

This article has described text analysis as a model of English syntax learning process. From the model implemented, it has been found out that in every segment of learning (input, language, and content), text analysis appears. Students enjoyed doing it through any kind of cooperative technique such as pair work, small group discussion, as well as question-answer. Even though this model consumes more time, the way students did the activities make them come up with their ideas, and step by step, it increases their ability to use the patterns of the English.

Since Syntax is the content subject which has stable rules and lack of variation, it implies that lecturers should work hard for the students' creative activities on learning. By considering the appropriate time, this model will be one of the workable solutions particularly in studying content subjects of English and other languages generally. 


\section{References}

[1]Agustien, I. R. H. 2006. Genre-Based Approach and the 2004 English Curriculum. Retrieved from http://aguswaryanto.files.wordpress.com on December 20, 2008.

[2]Jacobs, Roderick A. 1995. English Syntax. New york: Oxford University Press.

[3] Radford, A. 1999. Syntax: a Minimalist Introduction. Cambridge: Cambridge University Press.

[4]Hellspong, Martin. 2001. Syntax. Retrieved on February, 2nd 2010. from http://sehthcio midmarket.techtarget.com/sDefmition/0,,sidI 83_gci213O8 1,00.htinl.

[5]Brown, H., Douglas. 2007. Teaching by Principles: An Interactive Approach to Language Pedagogy. San Francisco: Longman.

[6]Thornburg, S and Harmer, Jeremy (Ed). 1999. How to Teach Grammar. New York: Longman

[7]Tract, L. 1995. The Importance of Syntax. Retrieved on February 18, 2010 from http://tratt.net/laurie/techarticles/articies/t he-itnportance_oLsyntax.

[8]Lunacy. 2005. Why Study Syntax? Retrieved from http://syntaxiunaci.blogspot.com/. on February 02, 2010.

[9] Mardijono, P.2004. The Hollistic Approach. http://portfolio.petra.ac.id. Retrieved on February 18, 2010

[10]Donohue, M. 2005. Morphology and Syntax. Retrieved from http://tsps.anu.edu.au/donohue/Syntax3.pd£ on November 04, 2009.

[11] Collins, Peter and Hollo, Carmella. 2000. English Grammar an Introduction. New York: Palgrave.

[12]Scocco, D. 2007. English Grammar 101: Sentences, Clauses and Phrases. Retrieved from http://www.dailywritingtips.com/sentences-clausesand-phrases/. on February 02, 2010.

[13]Nordquist, R. 2010. Syntax. Retrieved from http://grammar.about.com/od/rs/g/syntax.htm on February 02, 2010.

[14]Werner, P.K and Lou Spaventa. 2002. Mosaic 1: Grammar. New York: Mc Graw Hill.

[15]Oshima, A and Ann Hogue. 2006. Writing Academic English. New York: Longman.

[16]Wekker, Herman and Liliane Haegeman. 1996. A
Modern Course in English Syntax. London: Routledge.

[17]Wheeler, K. L. 1998. Clauses and Phrases. Retrieved from http://gram-clauses_n_phrases.html/ on March 04, 2010.

[18]Siegel, J.2001. How to tell the difference between a sentence, a clause, and a phrase. Retrieved on March 04, 2010 from http://people.hsc.edu/ddclassicsALatin/generalaboutgr ammar/clauses.shtm

[19]Simmons, Robin L. 2010. The Clause. Retrieved on 3rd August 2010 http://utminers.utep.edu/RbSimmons/eng10310/clause 1.html.

[20] Fitzpatrick, M. 2005. Engaging writing: Paragraph and Essays. New York: Longman.

[21]MacFadyen. 2009. Building Phrase. Retrieved on 3rd August 2010. http://www.uottawa.ca/academic/arts/writcent/hypergr ammar/bldphr.httnl

[22]Gleason, B. J. and Ratner, B. N. (Ed).1998. Psycholinguistics. Orlando: Harcourt Brace College Publisher.

[23]Marina, Valerija. 2006. Text- Based Language Teaching and the Analysis of Tasks Presented in English Course Books for Students of Information Technology and Computing. Retrieved on March 27 th. 2010.

[24]Williamson, O. M.2005. How to Analyze a Text. Retrieved from http://utminers.utep.edu./omwilliainson- on November 04, 2009.

[25]Clandfield, Lidnsay. 2005. Text in language classrooms: TALO, TA VI and TASP. http://www.teachingenglish.org.uk/think/articies/textlanguage-classrooms-talo-tavitasp. Retrieved on Juli 12 th, 2010.

[26]Wigniewski, K. 2006. Discourse analysis. Retrieved from httpi//

[27]Djiwandono, Patrisius. 1995. "A Model for Developing Coherence and Authenticity in ESP Materials". ETF. Vol. 33.No.2. April.pp 4143

[28] Palmer, R. 1982. "Information Transfer for Listening and Reading". ETF., Vol 20. No.1 pp: 29-33 